\title{
COMPARATIVE STUDY ON BEHAVIOR OF ELEVATED WATER TANK WITH SOIL STRUCTURE INTERACTION SUBJECTED TO SEISMIC LOAD USING SAP 2000
}

\author{
Tejaswini M.S ${ }^{1}$, Sridhar. $\mathbf{R}^{2}$ \\ ${ }^{I}$ M.Tech student, Bengaluru, Structural Engineering, NCET, Karnataka, India \\ ${ }^{2}$ Sr.Associate Professor, Department of Civil Engineering, NCET, Karnataka, India
}

\begin{abstract}
The Elevated water tank is incredibly necessary for the society, In this present work, comparative study of elevated water tank for different Zones of Zone 3 and Zone 5 was done by using the SAP 2000 Software and the structure is taken for comparative Study for different soil condition that is Soft, Medium and Hard Soil condition, concluded the final result of displacement and Drift of the structure and also discussed the graph for Base shear and the time period graph. The different Water tank model shapes considered. i.e, Circular elevated tank with load and without load condition, Rectangular elevated tank with load and without load condition., Square elevated tank with load and without load condition.
\end{abstract}

Keywords: Tall structure, Regular, vertical Irregular, Lateral Displacement, Lateral Drift, Base Shear, Time period.

\section{INTRODUCTION}

The importance was given to study the elevated water tank, using finite element method with different soil condition. The elevated water tank is also known as elevated service reservoir (ESRs) its effectiveness play an important part of water supply system. The push over analysis is having permanent vertical loads \& gradually increases in the horizontal loads to computerize the deformation as well as damage pattern of a structure. The columns and braces are critical parts so this has to be designed carefully for the wind and EQ loads. It mainly depends upon the soil condition and dynamic characteristics of the structure. As per the code book IS: 1893 (part 1) 2000 more than 60\% of India is prone to EQ seismic analysis of elevated water tanks differ from other structural in two ways.

At the time of seismic exultation the liquid inside the tank exerts hydrodynamic force on tank water \& base. In comparison of other structures liquid containing elevated water tanks have low ductility and redundancy loading to necessity of increased designed seismic forces. Thus this structure required precise estimation of design EQ load \& careful seismic analysis.

An elevated water tank is important structural aspect used for the water resources for distribution of water with high pressure. It is very necessary for the industrial and factories for the storage of liquid especially in chemical factories. So this must spoil or distribute during earth quake.

The water tank contains the foundation, column tank and water. The load of water is supported by tank and there both load supported by columns and all these elements will depend on the foundation.
During the earthquake the tank get fails due to huge mass age of the water and directly or indirectly it will affect the water resources in the distribution of water where frequently earth quake occur. Hence seismic behavior has been examining from the past years.

Due to the lack of knowledge of supporting system some of the water tanks were collapsed or heavily damaged. So there is need to focus on seismic safety of lifeline structure with respect to alternate supporting system which are safe during earthquake.

The analysis mainly depends on moment and capacity of the water containers. The main aim is to comparative study on square tanks.

Rectangular tank is very beneficiation structure for the resistance of earth quake. Rectangular water tanks were also damaged during previous days \& it was resulted in spillage of dangerous chemicals \& is reacted in environment \& was lead to caught the fire For all these some researchers were done for specific topics on rectangular tank \& also similarly induced bending moments of the walls was done for model for fluid rectangular tanks

\subsection{Methodology}

In this project SAP 2000 software has used for the design of elevated water tank with soil structure subjected to seismic load. It is a better software when compared to other software \& is very rarely accessible. Some parameter at different condition has follows.

1. Square shaped evaluated water tank with zone $2,3,4,5$ \& conditions are type medium hard

2. Rectangular shaped evaluated water tank with zone 2,3,4,5 \& soil conditions are soft, medium \& hard 
3. Circular shaped evaluated water tank zone $2,3,4,5$ \& soil conditions, soft, medium \& hard

\subsection{Aim and Scope}

The aim of the study is to analyse the behavior of elevated water tank with different height and shape subjected to seismic loading and soil conditions.

1. The different shapes like square, rectangle and circular shapes of water tank are done at different soil conditions.

2. The height of water tank are varied based on the capacity of the tank

3. Capacities of the tank considered are 5 lakh, 10 lakh and 15 lakhs liters of water.

4. The ground soil conditions considered are soft, medium and hard soil.

5. The analysis is performed for equivalent static method for different zones is zone 2,3,4 and 5 respectively

6. The parameters of these results considered for the analysis are Displacement, Drift ,Base shear and Time period.

\section{MODEL DESCRIPTION}

1. Structure - water tank

2. Types - square, rectangular \& circular

3. Height $-3.5, \& 10.5$

4. Grade of concrete - M30

5. Grade of steel $-\mathrm{F} 45$

6. Beam size $-300 \times 500$

7. Column size $-300 \times 300$

8. Slab size $-15 \mathrm{~mm}$ thick

9. Seismic zone - II, III, IV \& V

10. Soil type - Soft, medium \& hard

11. Importance factor - II

12. Reduction factor -3

13. Water load -1

Square evaluated water tank having the dimension $12 \mathrm{~m} \mathrm{x}$ $12 \mathrm{~m}$ with different heights $3.57,10.5 \mathrm{~m} \&$ also comparatively studied with different capacity of tank i.e. 5 Lakhs liters, 10 lakhs liters, 15 lakhs liters respectively

The 3D model is done for the analysis \& it is considered load pattern according to Indian standards with dead load \& water load. similarly Rectangular \& circular evaluated water tank is carried out for comparative studies similarly evaluated water tank is taken with seismic $9 \times 16 \mathrm{~m}$ with different height $3.5 \mathrm{~m} 8 \mathrm{~m} \& 10.5 \mathrm{~m} \&$ also comparatively studied with different capacity of tank i.e. 5 lakh liters, 10 lakhs liters 15 lakhs liters respectively Circular evaluated water tank having the radius with different heights $3.5 \mathrm{~m}$, $7 \mathrm{~m}, 10.5 \mathrm{~m} \&$ also comparatively studied with different capacity of tanks i.e. 5 lakhs liters, 10 lakhs liters, 15 lakhs liters respectively The 3D model is done for the analysis \& it is considered load pattern accordingly to Indian standards with dead load \& water load.

\section{RESULT AND DISCUSSION}

The results obtained from the analysis are represented as graph and discussed. The parameters considered for the discussion are displacement, drift, base shear and time period. The comparative graph is plotted for both zone-3 and zone-5 for the circular, rectangular and square modes with and without water load conditions. .

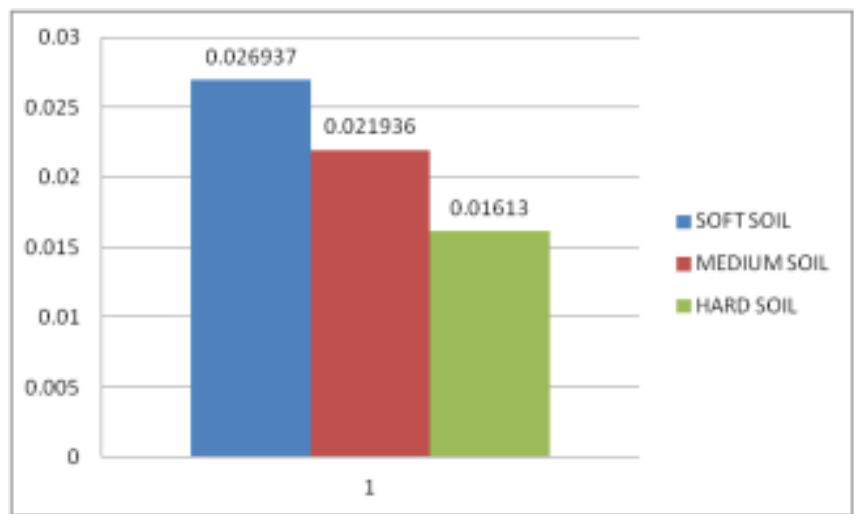

Chart -1: Graph Shows Max Displacement of Square Water Tank For Zone 5 and Height 10.5

Chart 1 shows the results of Square tank with load at three different heights for this height the graph is plotted for displacement. The displacement graph got the result at Zone 3 soft soil shows Maximum displacement and also at Zone 5 soft soil shows Maximum at height of $3.5 \mathrm{~m}, 7 \mathrm{~m}$ but at height of $10.5 \mathrm{~m}$ soft soil shows Maximum displacement. The maximum displacement of the Square tank in soft soil was found to be $0.026937,0.021936$ for medium soil and 0.01613 for the Hard soil. The reduction percentage of medium soil for $18.56 \%$ and for hard soil is $40.11 \%$ when compared with soft soil.

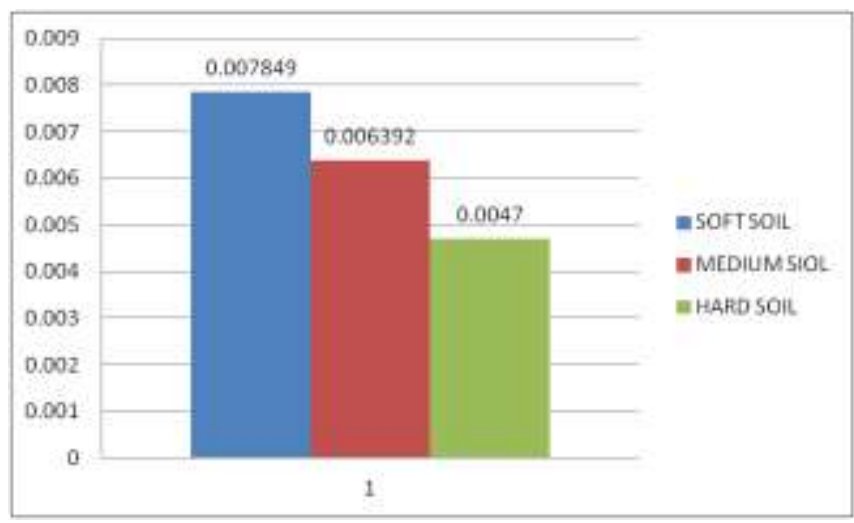

Chart -2: Graph Shows Max Drift of Square Water Tank For Zone 5 and Height 10.5

Chart 2 shows the results of Square tank with load at three different heights for this height the graph is plotted for drift. In the drift graph got the result at Zone 3 soft soil shows Maximum drift and also at Zone 5 soft soil shows Maximum at height of $3.5 \mathrm{~m}, 7 \mathrm{~m}$ but at height of $10.5 \mathrm{~m}$ soft soil shows maximum drift. The maximum drift of the Square tank in soft soil was found to be $0.007849,0.006392$ for medium soil and 0.0047 for the hard soil. The reduction percentage for medium soil is $18.56 \%$ and for hard soil is $40.11 \%$ when compared with soft soil. 


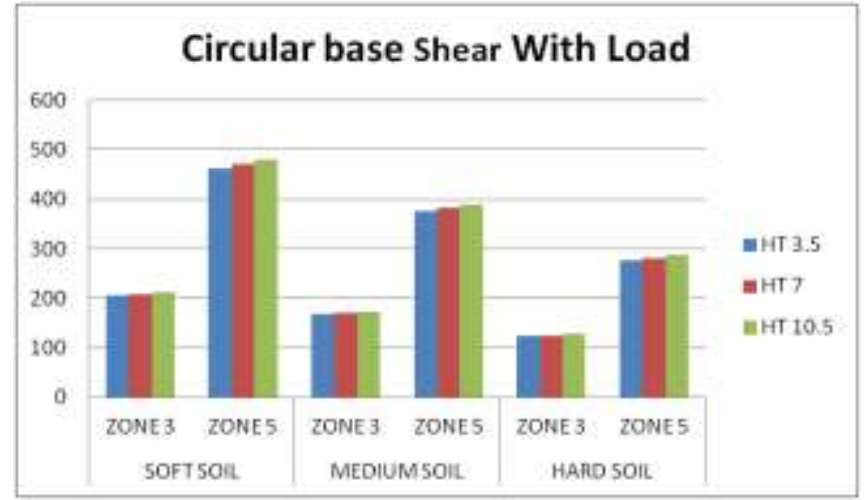

Chart -3: Base Shear Graph for Circular Elevated Water Tank With Load

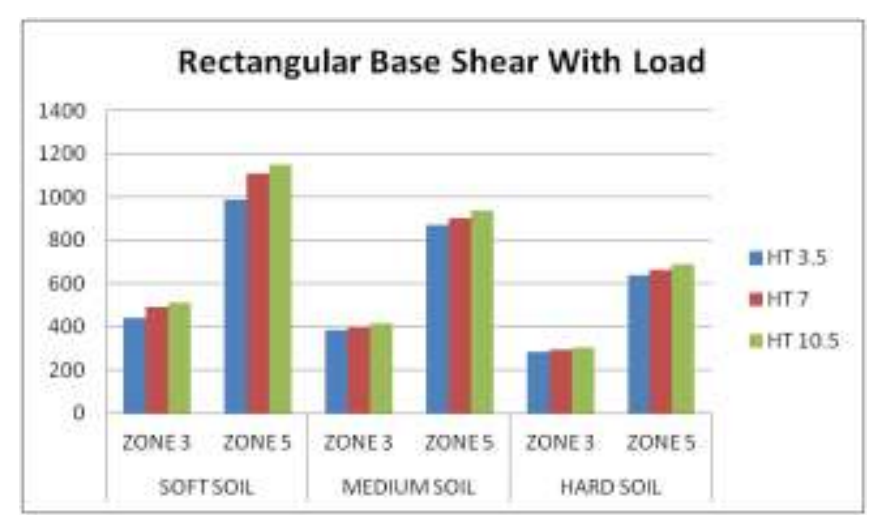

Chart -4: Base shear for rectangular elevated water tank with load

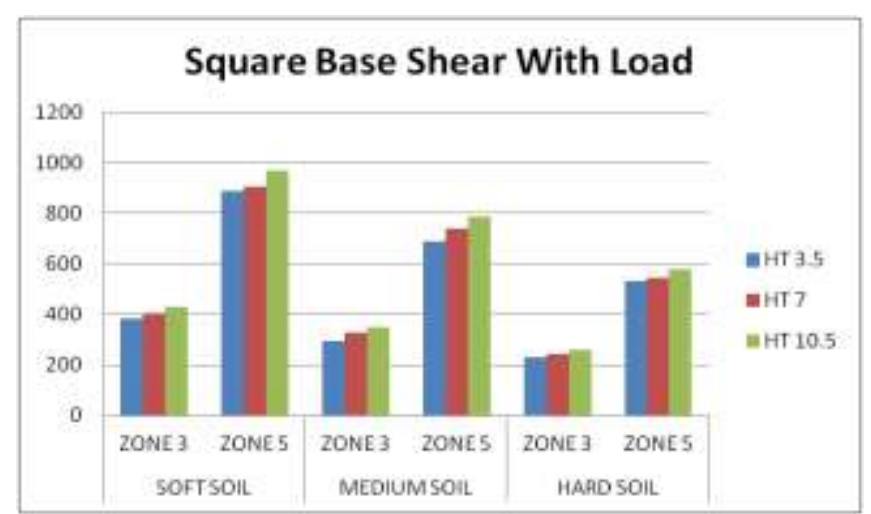

Chart -5: Base Shear for Square Elevated Water Tank With Load

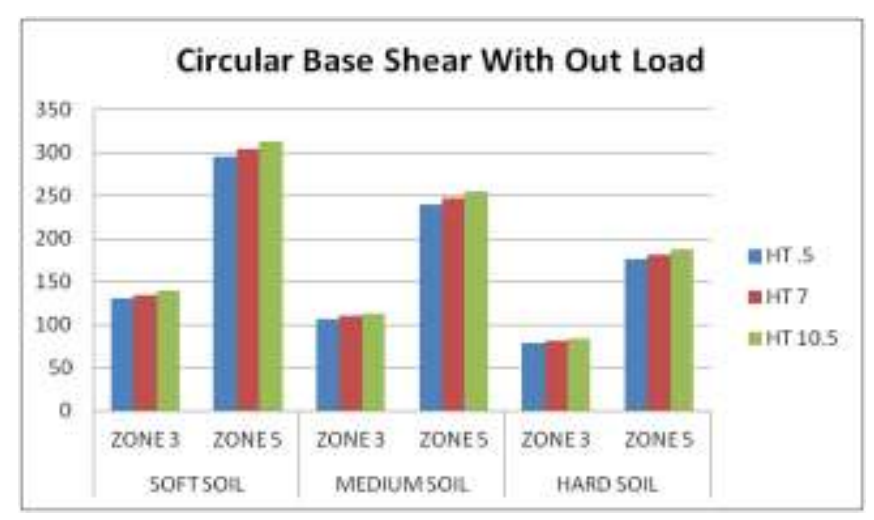

Chart -6: Base Shear Graph for Circular Elevated Water Tank without Load

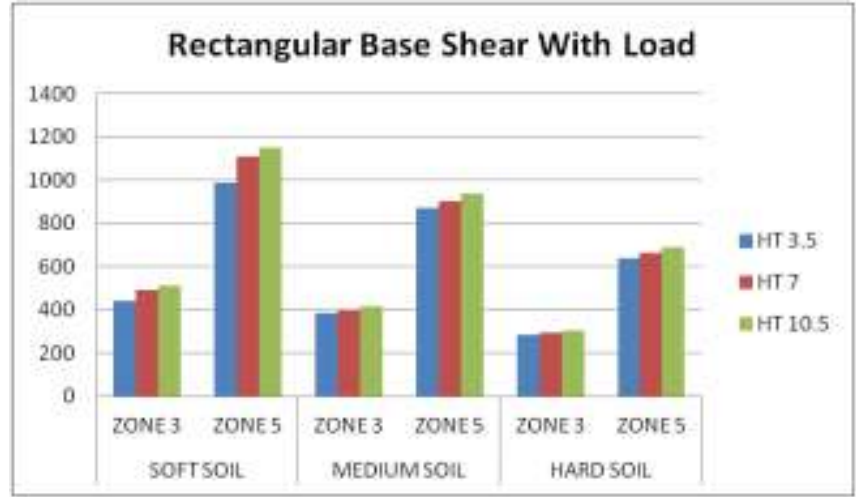

Chart -7: Base shear for rectangular elevated water tank without load

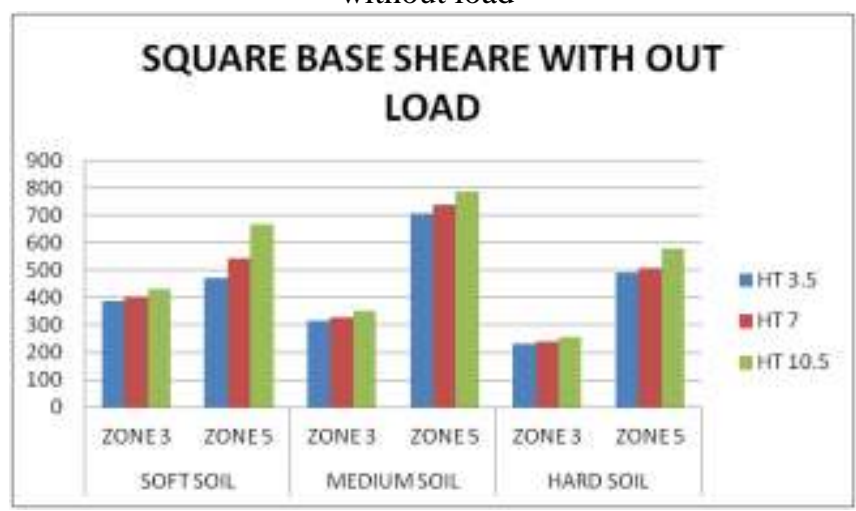

Chart -8: Base Shear for Square Elevated Water Tank with Load

Chart 6 and 7 shows the graph of base shear values for the circular elevated tank, rectangular elevated square elevated tank respectively without load for soft soil, medium soil and hard soil at the height of $\mathrm{h}-3.5, \mathrm{~h}-7, \mathrm{~h}-10.5$. In the above circular base shear graph the comparative study for zone 3 and zone 5 is done for every type of soil. In the circular base shear graph in zone 5 for soft soil shows maximum value of base shear especially tank at the height of 10.5 shows maximum base shear value without load water tank. Similarly for the rectangular and square base shear graph in zone 5 for soft soil at the

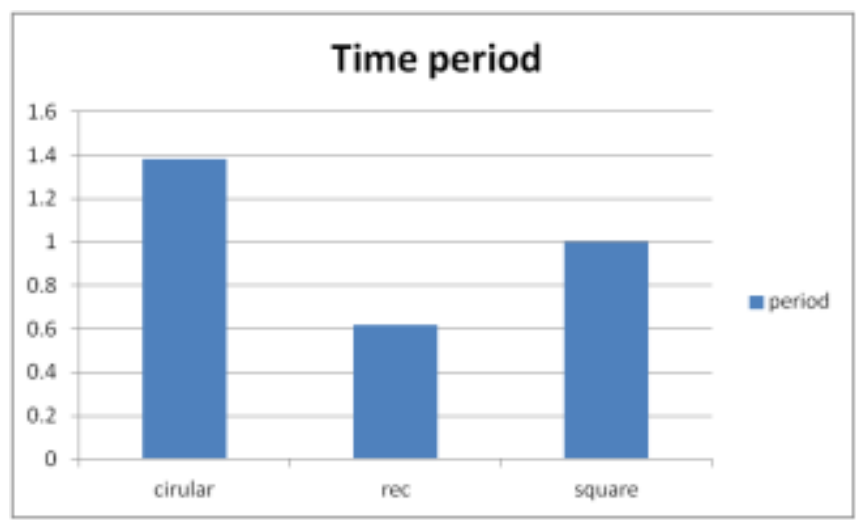

Chart -9:Time Period for Circular, Rectangular, Square Elevated Water Tank

Chart 9 shows the graph of fundamental time period for the circular elevated water tank got maximum value among the circular, rectangular and square elevated water tank 
respectively. In this the with water load or without water load does not matter for the time period graph economically. the rectangular elevated water tank is more strengthened than other two circular and square elevated water tank and the circular elevated water tank is more time period than the rectangular elevated water tank and the square elevated water tank finally it shows that the rectangular elevated water tank is more strengthened due to seismic load according by the analysis is shown in the form of graph height of 10.5 for elevated water tank got maximum value.

\section{CONCLUSION}

The parameters considered the displacement, base shear and time period. To analyze the seismic behavior of structure, models are subjected to seismic load as per IS 1893:2002. Following conclusions are made for different cases considered in the soft, medium and hard water tank

1. In the circular elevated water tank with load the displacement and the drift value for soft soil as more. It concludes that the structure is stiffer in the hard soil at zone 3 and zone 5 at the height of $3.5 \mathrm{~m}, 7 \mathrm{~m}$, and $10.5 \mathrm{~m}$ respectively.

2. In the circular elevated water tank without load the displacement and the drift value for soft soil as more than the other. It may conclude that the structure is stiffer in the hard soil at zone 3 and zone 5 , at the height of $3.5 \mathrm{~m}, 7 \mathrm{~m}$, $10.5 \mathrm{~m}$ respectively.

3. In the Rectangular elevated water tank with load the displacement and the drift value for soft soil as more than the other cases. This structure is stiffer in the hard soil at zone 3 and zone 5 , at the height of $3.5 \mathrm{~m}, 7 \mathrm{~m}, 10.5 \mathrm{~m}$ respectively.

4. In the Rectangular elevated water tank without load the displacement and the drift value for soft soil as more than the other. it conclude that the structure is more stiffer in the hard soil at zone 3 and zone 5 , at the height of $3.5 \mathrm{~m}, 7 \mathrm{~m}, 10.5 \mathrm{~m}$ respectively.

5. In the Square elevated water tank out load the displacement and the drift value for soft soil as more than the other. The structure is stiffer in the hard soil at zone 3 and zone 5 , at the height of $3.5 \mathrm{~m}, 7 \mathrm{~m}, 10.5 \mathrm{~m}$ respectively.

6. It was concluded that the structure is stiffer in the hard soil at zone 3 and zone 5 , at the height of $3.5 \mathrm{~m}, 7 \mathrm{~m}, 10.5 \mathrm{~m}$ respectively

\section{REFERENCES}

[1] Keyur Y Prajapathi, Dr.H.S Patel, Prof A.R Darji "Economical aspects of hybrid staging systems for elevated storage reservoir" global journal for research analysis published on $1^{\text {st }}$ July 2014.

[2] Gareane A, Algreane, S.A Osman, Othman.A Karim and Anwar Kasa "Dynamic behavior of elevated concrete water tank with alternative impulsive mass configuration published on May 2016

[3] Jiten B Thaker, siddarth G Shah "Quantifying the effect of soil flexibility for elevated storage reservoir by push over analysis" International journal of scientific and engineering research published on May 2016
[4] R. Livagalu A Dogangun "Simplified seismic analysis procedure for elevated tanks considering fluid structure - soil interaction" journals of fluids and structure on year December 2005

[5] Miss. Sonali M.Maidankar, Prof G.D Dhawale, Prof. S.G Makarande "Seismic Analysis of Elevated circular water tank using various bracing system" international journal of advanced engineering research and science published on Jan 2015

[6] Dhiraj Virkhare prof Laxmikant Vairagade, Vikrant Nair, "Push over analysis of water tank staging" international research journal of Engineering and technology published on July 2015

[7] F Omedinasab and H.Shakib "Seismic vulnerability of elevated water tank using performance based design" the $14^{\text {th }}$ world conference on earthquake engineering published on October 2008

[8] Ankesh Birtharia and sarvesh K Jain "Seismic response of elevated water tanks "An overview international research journals of engineering \& technology published on July 2015.

[9] Neha N Walde, Sakshi monchalwar, Amey khedkar "seismic analysis of water tank considering effect on the period international journal of research in Engineering and technology published on June 2015.

[10] Nishiganda R Patil, Rajashekar.S Talikote "Seismic behavior of elevated water tank" international journal of research in Engineering and technology published on May 2015 